\title{
"La Epopeya de América", por Edgardo Ubaldo Genta
}

\author{
América tiene \\ ya su poeta.
}

Con una obra de gran relieve literario, Genta vuelve a presentarse en el escenario de la literatura americana. Esa obra es realmente extraordinaria $y$, sin duda alguna, la primera en su género.

Genta la intitula La epopeya de América. ¿Es realmente una epopeya? Dentro del concepto clásico, no, pero dentro del concepto moderno que excluye ciertas exigencias retóricas, sí, la obra es una verdadera epopeya. $Y$ lo es por el asunto que trata, por la forma de tratarlo y por ese ambiente de heroicidad que la envuelve. Claro está que lo heroico no es para Genta lo que sería para un griego y un romano y acaso para un francés del medioevo; para él lo heroico tiene un valor nuevo, y más que en la acción, la heroicidad se manifiesta en las ideas.

$$
\text { * * * }
$$

Hecha esta pequeña digresiớn, entraremos a considerar la obra en sí misma. Para nuestra apreciación, puede considerársela en estos tres aspectos:

$1^{\circ}$ La concepción en sí de la obra;

$2^{9}$ Su plasticidad histórica, o sea el ambiente histórico que la envuelve; en este ambiente caben tanto los hombres como las cosas; acaso podríamos llamarle la arqueología de la epopeya; y por último:

$3^{\circ}$ Su realización. 
Estos tres aspectos compendian dos elementos subjetivos y uno esencialmente objetivo; imaginación, plástica y estética.

$$
\text { * * * }
$$

La obra empieza con un prólogo. Vale decir, con una invocación. O como lo sería para Goethe, con una introducción. La escena es dramática. Los personajes parece que hablaran para el tiempo, desde la cumbre de los tiempos. Por estar muy altos, los pueblos no escuchan, o mejor dicho, no sienten las voces; pero sobre ellos caen las simientes de la siembra astral. El numen de América habla con Bolivar; no, se inclina ante Bolívar y le dice:

$$
\begin{aligned}
& \text { tu visión, tu Delirio! } \\
& \text { la más bella Verdad del Nuevo Mundo! } \\
& \text { la más grande Epopeya de los Siglos! }
\end{aligned}
$$$$
* * *
$$

Del prólogo pasamos a la epopeya dramatizada, pero el drama está precedido de otro prólogo. En él se pinta una naturaleza esencialmente histórica, arqueológica. También en este cosmos primitivo el animismo y el totemismo juegan un papel importantísimo, al par que las leyendas dan colorido ingenuo al ambiente. Por lo abarcante de la evocación, el poeta se hace heroico, parnasiano y a veces simbolista.

Así dice:

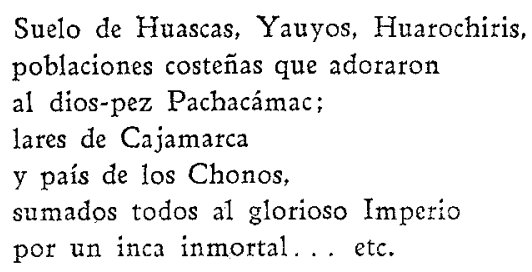

Es admirable toda esta evocación y en ella alternan la historia, las tradiciones y los mitos. Todo parece arrancado de un ambiente de piedra. Bajo el conjuro admirable de la poesía, surge la América precolombiana; la América paleolítica y neolítica, mítica y arqueológica. E1 poeta canta: 


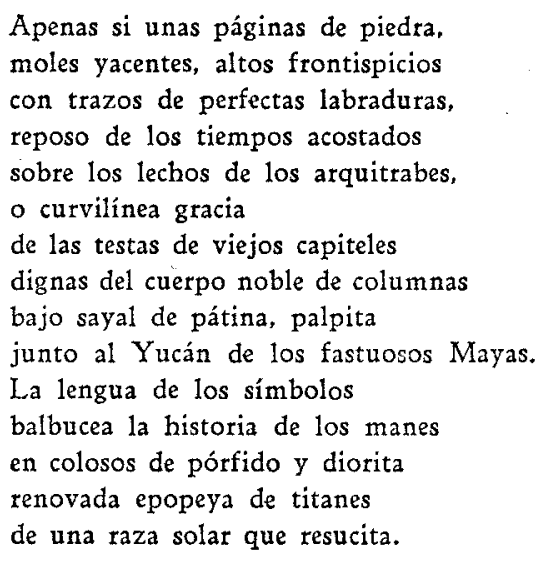

Pero a diferencia de los parnasianos, el poeta se torna a su lirismo y exclama:

Hija del mar principio de la vida, perenne gracia de inquietud proteica, belleza henchida de renovaciones, el Sol te vió crecer plena de dones sobre la rosa de infinitas rutas, formas nobles, sublimes, impolutas, joven América, corazón profundo, promesa y gloria de la Humanidad. Yo te sueño en la luz, viva y desnuda de polo a polo, como imán del mundo danzando el ritmo de la eternidad!

$$
* * *
$$

Después da una admirable evocación de Cuzco, la joya de la arquitectura bárbara "dormida sobre el lecho de sus valles". Este canto evocador, plástico y sugestivo, tan lleno de pasado como de presente, termina en forma realmente magnífica:

$\mathrm{Y}$ muy 1ejos, muy alto, contra el cielo,

vigía de la luz, loco de vuelo, vencedor en celestes paroxismos, dominando el espléndido conjunto el Cóndor de los Andes, como punto de la interrogación de los abismos. 
Sí, el cóndor, el gran señor de las soledades de las cimas, el único que a través del tiempo y del espacio no ha perdido su indómita bizarría ni la belleza salvaje de pisotear las cumbres, que lo ha transformado en símbolo viviente de todo lo que se agita sobre lo pequeñamente transitorio. Esta visión final no podía faltar al evocarse a Cuzco, la ciudad de piedra despedazada, pero no reducida a polvo por el tiempo.

$$
\text { * * * }
$$

Después el canto IV. El elemento vivo de la evocación:

$$
\begin{aligned}
& \text { Por el compás la multitud frenética } \\
& \text { su concentrado vértigo desfoga } \\
& \text { moviendo a un tiempo la famosa soga } \\
& \text { que llaman "Huasca" } \\
& \text { guardada cual tesoro en Moro Urco, } \\
& \text { notable por su trenza de colores } \\
& \text { con hilo de oro y plata, } \\
& \text { que en dos borlas riquísimas remata. } \\
& \text { Plástica danza de ondulantes giros } \\
& \text { con cuyo adorno el vencedor se guarne } \\
& \text { y que proclama, en gestos } \\
& \text { sonrisas y suspiros, } \\
& \text { la victoria perpetua de la carne. }
\end{aligned}
$$

El poeta hace historia, pero historia emotiva y libre de esas reglas fijas que se imponen los historiadores. Por suerte el historiador no ha eclipsado al poeta.

Luego, los personajes. ¿Qué vida tienen estos héroes autóctonos! Así debieron ser, acá son más grandes, más bellos, más reales que en la historia. En la poesía sufren y sienten; en la historia pasan como jefes, o simplemente como hombres. Es que la historia es fría como las piedras. En cambio, la poesía tiene calor de sueños. En la historia estos personajes nos admiran, en la poesía nos hacen sufrir, se humanizan, tienen vida, están más cerca de nuestro corazón. En magnífica síntesis, el poeta nos lo presenta: 
Huáscar es la cabeza del Imperio

$Y$ es Atahualpa el corazón y el brazo.

El uno sueña en abismal regazo:

ciencia, infinito, eternidad, misterio...

E1 otro siente

que le golpea el corazón ardiente

la sangre de los bravos generales

Vicaquiraus y Maytas.

orfebres de victorias inmortales.

$Y$ enfermo el viejo Inca,

quizá su amor superhumano a Pacha,

va el hijo de ambos

al frente del ejército

para imponer en los distantes reinos

la euritmia incaica, la expresión genérica

que toda cruel limitación depasa:

¡E1 Imperio Solar! nombre sublime

de la unidad de América.

* * *

Después el canto consagrado a los conquistadores. Todo lo que pueda decirse de ellos, está contenido en este diálogo admirable:

Tollán

-Verás joh noble Villacuma! - Aquellos

graves, audaces, bellos

dominadores de la mar y el campo

son, por igual, soldados y marinos.

Tropel contradictorio;

unos, enceguecidos

por el ansia de gloria y de riqueza

e invulnerables bajo sus metales;

otros, dulces, serenos,

con las sublimidades de los éxtasis

y cubiettos con cándidos sayales...

Villacuma

- ¿Que dices?

Tollán

- Lo que escuchas, gran Señot.

Oro, cuerpo, conciencia te arrebata, que Espada y Cruz trae el Conquistador. 


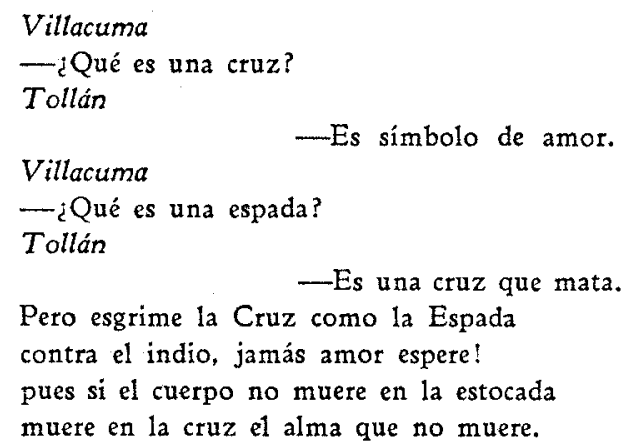

La pintura de aquellos héroes de la conquista no puede ser más exacta y coincide con ella Gonzalo de Reparaz, cuando escribe: "A estos conquistadores, inhumanos siempre y que a menudo no pasaban de una sencilla mezcla de aventureros y bandidos de mentalidad elemental, se les debe el haber revelado a la humanidad, arrostrando todos los peligros de una naturaleza desconocida, un continente. Recordemos, para su descargo, que su bandolerismo y crueldades sin cuento no son ni más ni menos que el mismo estigma vergonzoso que selló toda la expansión europea: portuguesa, inglesa, francesa, holandesa. Comerciantes y piratas, ladrones y asesinos, misioneros, formaban, en verdad, una turba abigarrada, que allá en el extremo Oriente, chinos y japoneses, hartos ya de ver tanta crueldad y tanto fanatismo, acabaron, con muy buen acuerdo, por expulsar de sus tierras, no pudiendo tolerar por más tiempo los ejemplos de barbarie sanguinaria y destructora que daban todos aquellos pueblos. Pero los americanos, menos fuertes y más primitivos, sucumbieron".

Ahora, pasaremos a considerar la Segunda Epoca. Los personajes que actúan en ella ya nos son más conocidos. Aparecen, entre otros, Bolívar, San Martín, Sucre, Olmedo, el gran cantor de la victoria de Junín, etc.

Sin embargo, las unidades temáticas e históricas nos vuelven, con toda lógica, a la época anterior.

Canta el poeta: 
La dispersa gleba India:

El Maya, el Azteca,

el Chibeha y el Quechua.

cumpliendo sagrado destino,

mezclada con sangre del Anglo-Sajón y del Neo-latino

plasmó el arquetipo de su plenitud.

Hecha la conjunción de las razas, conquistadoras y aborigenes, Genta la individualiza con este sello inmortal:

$Y$ como recuerdo del magno suceso,

sobre el gran pórtico del Sur

la mano serenisima del Creador eterno

tomó cuatro estrellas

e hizo con ellas

la señal de la Cruz.

Rodó nos dice: "el Crucero, cuyos brazos abiertos se tienden sobre el suelo de América como para defender una última esperanza".

El canto XI es de un colorido vivaz, sevillano. En él, el poeta nos enfrenta a una emotiva evocación histórica en la cual se unen, en discorde, aunque en armonioso ritmo, algo de la mitología grecoromana con nuestro mundo autóctono.

Veamos un ejemplo:

Después fué la lberia;

un índice de audacia, bauprés de Marco Polo, mostró las nuevas claves de Neptuno y de Eolo.

Marchando hacia las vagas rutas de Nueva Hesperia

ya ni en la soledad el hombre se hallaba solo;

la brújula y la pólvora dieron valoración

a lúcidos vaticinios de Séneca en la Medea;

con los nuevos descubrimientos

todos se descubrieron héroes de su odisea

y en heteróclita exaltación

se embriagaban los elementos con la rosa de los vientos

y las pasiones humanas con el clavel del cañón. 
Para algunos lectores desprevenidos, Genta habria incurrido en el error de Ercilla. Sin embargo, a nuestro juicio, el poeta puede salvarse de esa crítica ya que tal unión no significa el transporte de elementos greco-latinos clásicos al Nuevo Mundo, sino, simplemente, un recuerdo oportuno de ciertas teorías geográficas que estuvieron en boga en el Renacimiento. E1 mismo Colón conocía aquel pasaje de "La Medea": "En que rompiendo el océano sus lazos, dejará ver una vasta región, Tethis descubrirá nuevas tierras y Thule no será el fin del mundo".

Es digna de destacarse esta hermosa evocación de la conquista:

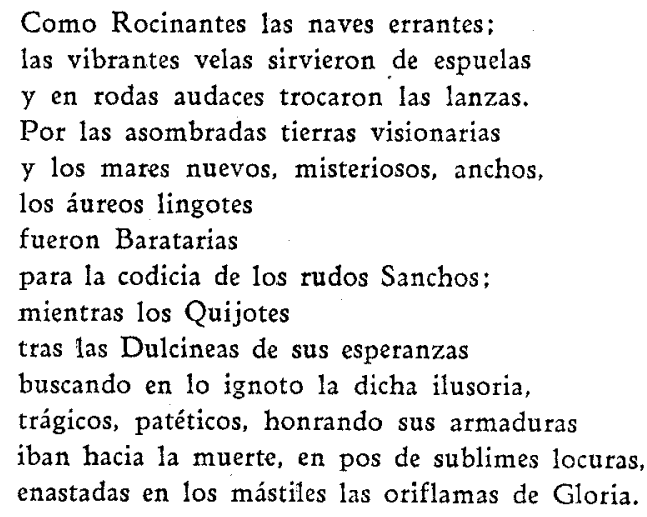

No cabe duda de que el poeta tiene del conquistador el mismo concepto de Reparaz, el autor a que ya hemos hecho referencia, pero sea como sea, a ese tipo atrevido y vencedor de mares se le debe el descubrimiento y colonización del nuevo continente. Espa. ña, especialmente, nos envió esta clase de hombres, pero con ellos, como dice el poeta peninsular:

$$
\begin{aligned}
& \text { su robusto idioma, } \\
& \text { sus leyes y su Dios. }
\end{aligned}
$$

Este canto podríamos llamarlo también "Canto de la Emancipación". En él nos encontramos con un nombre sentidamente familiar, el de Artigas.

Con alto vuelo lírico, el autor nos presenta un desfile de colores que son como el anticipo de las banderas patrias. 
Dice así:

Dos veces las fuerzas austeras

juntaron las nuevas banderas:

el blanco, el celeste, el rojo, el oro, el azul...

catalisis de colores, fiesta de metales, justa de fulgores

y de sonidos triunfales

en las dianas inmortales.

Júbilo de un continente

consciente

de su esplendente juventud...

Resulta también interesantísima la presentación de los guerreros americanos :

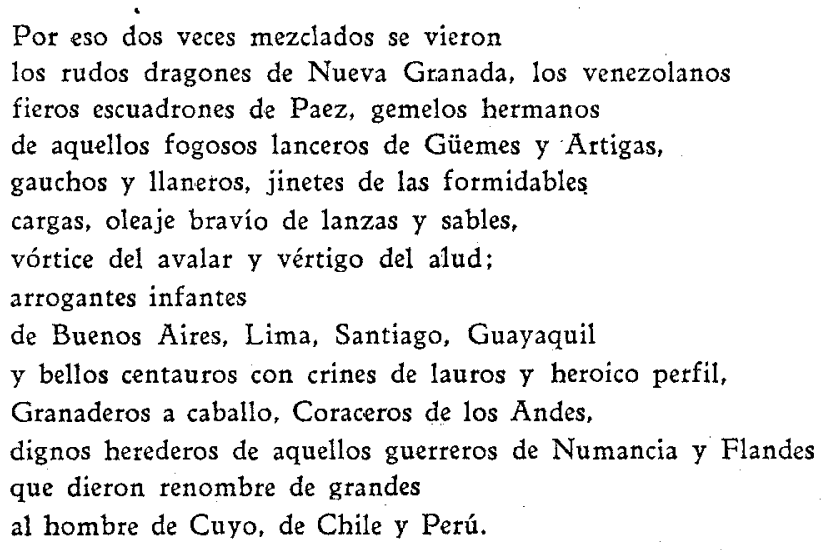

$$
\text { * * * } *
$$

El canto XII lleva esta leyenda: "España y América”. Los versos de este canto suenan a bronce. Son bélicos. Marciales. Onomatopéyicos. Destaco de él lo que podríamos llamar el alegato de la emancipación :

Señor Capitán de Navio; oíd y juzgad:

en nuestra santa lucha vibra conflicto eterno.

Alzamos la bandera del americanismo

no contra el amoroso derecho materno, 
sí contra el despotismo

tutelar.

No es lo mismo

sistema transitorio que espíritu racial.

Abatimos el Régimen!

la Raza no morirá!

Destaco, también, estos otros tan augurales:

No España, no Inglaterra ni Pottugal,

no el Negro ni el Indio mueren en nosotros. Se renueva

la Vida. De un Viejo Mundo nace una América Nueva.

Ella es la juventud de toda la Humanidad!

En este canto, hasta las palabras de la Nusta se precipitan al futuro.

Dice así:

Ved a la nueva tripulación

-oro y púrpura-

toda ella estremecida por la fuerza de sus ansias!

Su mente vela en la brújula!

Su corazón canta en las distancias!

Su puño vibra en el timón!

En síntesis, podemos afirmar que por todo este pasaje se desliza una ráfaga heroica. Hay en él mucho de nuevo, pero también odres viejos que sirvieron para contener la savia nueva. Aunque esencialmente lírico, el poeta se interna en los dominios de lo épico y lo estremece, con ese estremecimiento de la linfa serena cuando la desgarra la piedra que cae. pañol :

España y América!... Nuevamente recordamos al poeta es-

América :

Esta es España atónita y herida, bajo el peso brutal del infortunio inerte yace la matrona augusta que en otros tiempos fatigó a la fama. La que surcó los mares procelosos buscándote, atrevida, en el misterio hasta que un dia, deslumbrando al sol, surgiste como Venus de las ondas.

(Nuñez de Arce) 
Sí, esa es la gran España caída, pero de ese gran derrumbe de glorias y de imperios ha surgido esplendorosa la América india. Con los ojos alucinados de horizontes nuevos, con los labios entreabiertos en la modulación de un canto de victoria y con las manos llenas de espigas amarillas. Sobre las ruinas heroicas y veneradas de la Madre Patria, se levantó la gloria de las nuevas repúblicas americanas. Que las estrellas indias lloren plegarias de luz sobre esos escombros de la España cruzadora de mares y conquistadora de tierras.

El canto XIV constituye una oda triunfal destinada a exaltar la majestuosa cordillera de los Andes.

Es verdaderamente magnífico este pasaje:

Oh sublime Cordillera!

Se dijera

que, brotando desde el piélago profundo

del Pacífico, una carga de ciclópeos escuadrones

desfilara frente al Mar;

orológica conquista de una meta

que rebosa de los ámbitos del mundo,

más atrás de todo término, Imás atrás!

desplegando sobre el cielo la bandera de los días

contra el mástil de los vientos;

y son cientos

y son miles y millones

de montañas que se lanzan en frenética cartera

sostenidas por las salvas de invisibles baterias;

y que van

saltando abismos, raudo el sable de los vértigos,

con un gran torrente en ristre y un alud en banderola

tras el frémito de todos los volcanes capitanes

que, con casco empenachado de gloriosas arrogancias

se abalanzan en procuta

de la Línea Ecuatorial. . .

Todas, todas delirantes del furor de las distancias!

todas ebrias del coraje de la altura!

a la intrépida conquista de la luz y el horizonte!

más allá!

Tal el grito y el aliento de la enorme perspectiva

de la pampa fugitiva

que vislumbra cada monte

en un impetu triunfal... 
Más allá!

Siempre, siempre más arriba!

Siempre, siempre más allá!

En esta exaltación encontramos algo de aquel verbo pujante de "Almafuerte" y también mucho de la elocuencia arrebatadora de Chocano. Es un canto verdaderamente épico, épico por la forma y épico por el contenido. A nuestro juicio, lo mejor del libro. No se puede pedir una onomatopeya más grandiosa. La cordillera nos atrae, la vemos surgir de la planicie, erguirse, tocar la nube y reflejar en las nieves de las cumbres, el diamante bruñido de las estrellas. A veces las palabras toman alientos de cataratas y dan la sensación de que se desprenden de una cumbre inalcanzable.

Asi dice:

Cordillera de los Andes!

Madre y prez de las Américas!

Fausto y dicha de los ojos, fragorosa lejanía;

vuelo, vuelo de lás cimas sobre el báratro marino,

loco dédalo de cráteres y apófisis,

picos, crestas y cadenas; viva, extraña sinfonía

de figuras fantasmales, que se pierden,

giran, vuelven, nos enciman,

nos enciman al crecer hasta el espanto;

chocan, bajan, se arremeten

y se rompen y rehacen con estrépito de luces y de sombras,

y cual naves se aparejan entre olas de un océano patético

las que ruedan en procura de una costa remotísima...

ah, velámenes ardientes, que sugieren mil ensueños de colores,

de contornos y de músicas sublimes!

Destaco de este vibrante poema heroico y grandioso, las expresiones siguientes :

"Vía Láctea de montañas sobre el piélago de América..."

"Fausto y dicha de los ojos, fragorosa lejania".

"Vuelo, vuelo de las cimas sobre el báratro marino".

"Picos, crestas y cadenas; viva, extraña sinfonía".

"Si tu olímpica grandeza sobtecoge hasta el espanto".

"En tu seno, cordillera, lo más infimo se agranda". etc, etc. 
Leyendo este pasaje, reconocemos el amor que el poeta alienta por la naturaleza. Pero aparte de esto, Genta descubre en esa mole gigantesca, un nuevo personaje, mudo, grandioso y lleno de maravillosas tradiciones. Es que los Andes forman parte integral de nuestra historia! Por sus caminos tortuosos pasaron los conquistadores, los aborígenes y más tarde los emancipadores. En medio de sus noches profundas, resonaron los cantos de victoria de los blancos y las endechas mojadas en llantos de los indios vencidos. Por esas cumbres anduvieron los soldados de San Martín y Bolívar buscando patrias irredentas; también por esas alturas anduvieron los ñustas de miradas lejanas y agresivas, y en el macizo de sus rocas se asentaron ciudades de perfecta arquitectura que hoy constituyen el asombro y la admiración del arqueólogo. Sí, la cordillera de los Andes forma parte de nuestra historia y tiene por consiguiente, para el americano, lugar de preferencia en la evocación del pasado. Lástima grande que Genta no le haya cantado al viento de la Pampa! A nuestro viento indígena que despeinó las cabelleras de los indios y de los gauchos y dió, también, impulsos inusitados a los caballos de los libertadores.

El resto del canto no tiene la grandiosidad de este poema heroico.

$$
* * *
$$

Llegamos a la última época. El poeta ha escrito: "América para la Humanidad". Esta expresión nos evoca la evolución del sentimiento internacional de América. sajona;

19. La América Latina independiente de la América anglo-

$2^{9}$ Ia "América para los americanos", conforme al alcance que ha querido dársele a la doctrina de Monroe; y

$3^{\circ}$ América para la humanidad. Esta última afirmación debe constituir, con ciertos reparos, desde luego, el ideal de todo americano. Una América abierta a todas las manifestaciones nobles del espíritu, como, también, a las laboriosas emigraciones que lleguen de extracontinente. No ha mucho tiempo, en un discurso que pro- 
nunciáramos en la República Argentina, deciamos: "Nuestra América se siente ya amenazada por peligros de extracontinente. Corrientes demoledoras la conmueven y ya empiezan a infiltrarse en nuestro medio $\mathrm{y}_{\mathrm{r}}$ a conmover a nuestras juventudes. Es necesario prevenirse contra la amenaza que llega. Que nuestro idealismo cívico no se vea atropellado por ideologías desnaturalizadas; que nuestra libertad no se sienta restringida por el imperio de la fuerza y que nuestra libre emisión del pensamiento no encuentre otras vallas que aquellas que levantan la moral y la justicia. No podemos cerrar nuestras fronteras a los que llegan de otras latitudes; no podemos negarle al europeo ni al asiático el derecho que tienen de acogerse a la tutela generosa de nuestras leyes; a ellos les debemos nuestra civilización y nuestra grandeza cívica. A ellos les debemos el secreto de la belleza arrancada a la entraña misma de las piedras y esta concepción que tenemos de las patrias libres. A ellos les debemos, también, el culto de lo grande, pero no podemos permitirles que lleguen para conspirar contra nuestra estabilidad; para violentar nuestra soberanía; para limitar nuestras libertades o para subyugar nuestras conciencias. Que lleguen, sí, y en buena hora, juntos con el de Australia y el del Africa, así como llegaron los otros. Nuestras ciudades y nuestras campiñas esperan brazos laboriosos. Que vengan, pero que no ignoren que no podrán atentar impunemente contra nuestras instituciones, ni profanar nuestros credos familiares; que vengan, pero que sepan que los pueblos de América están unidos por fuerzas superiores; que vengan, pero que no pretendan sembrar discordias entre la gran familia americana. Que vengan, sí, pero que vengan a traernos la luz de sus cerebros, la habilidad de sus manos laboriosas, un concepto más puro, si es posible, de la belleza, sus cargas de dolores irredentos y hasta el hambre sagrada de sus hijos. Y entonces, 'sea la América para los americanos y para todos los hombres del mundo que en ella levanten su hogar, tierra de paz, de trabajo, de consuelo, de amor'."

Genta, aparte de ser un gran poeta, es también un doctrinario augural en las relaciones de los pueblos. Por lo tanto, no podemos escatimarle un sincero aplauso.

Los personajes de esta Tercera Epoca ya están más cerca de nosotros. Son más nuestros en el tiempo. 
El canto XVII empieza con un romance evocativo. Estamos en el Río de la Plata. Epoca posterior a la emancipación.

Los personajes reflejan admirablemente la inquietud del momento histórico que viven. Estamos en el período de la formación de las nacionalidades; por consiguiente, todavía no se han delineado bien los organismos políticos. Todavía el héroe militar está intimamente ligado al héroe civil y a veces se confunden.

Reafirmando su credo de crear una América para el mundo, el poeta dedica sentidas estrofas a las legiones extranjeras.

Canta el poeta:

-Coldados españoles: ¿no desangró su entraña maternal en América la dolorosa España? ¿No ha suftido bastante nuestra raza tenaz? Oid a vuestro Cónsul: todo guetrero hispano dejará los baluartes. Lo manda el Soberano. iA deponer las armas y a trabajar en paz! -Yo reclamo lo mismo, Legionarios franceses. Francia es la luz. Por ella dejad las falsas preces de la barbarie - ¿Dadme la enseña tricolor: -Es la voz de Inglaterra, marineros; que os manda desarbolar la nave de esta lucha nefanda.

- Y en el nombre de Roma, concluya aquí el horror!

En el canto XXI se reafirma esa comunidad internacional, tatificándose el concepto en las últimas estrofas de la obra.

Dicen así :

América es la patria de todos los que aman; sus hijos homos rayos de un sol de libertad; sustentamos el lema: todo para la Patria, la Patria para América y para la Humanidad.

$$
\text { * * * * }
$$

Hagamos, ahora, una ligera incursión por esta última época. De su lectura sacamos las siguientes conclusiones:

1. Un gran anhelo de confraternidad universal;

2a Un deseo vehemente de constituir la comunidad americana;

3ạ Una fervorosa prédica de paz, y por último, la consagración de un reverencioso culto a los héroes de América. 
Con marcado júbilo canta el poeta:

-No, no es esa

todavía la clara, la más honda,

la más definitiva, la suprema

voluntad de las almas!

Despojaos

de las armas! - Ah, más: abrid las puertas!

Más aún! — Impulsad los corazones

a que penetren en su amor, por fuerza

del mismo amor! - No, más todavía!

Traed las fulgurantes herramientas!

A derribar los muros de la heroica,

prodigiosa y eterna

Ciudad! - Hagamos su dolor fecundo!

Abridla toda plenamente! Vedla

como un premio de Dios! URBI ET ORBI

La ciudad proyectada sobre el Mundo!

La Epopeya de amor, gloria de América!

Todos

-El Mundo! -El Nuevo Mundo!

Esa es también nuestra doctrina americanista. La unión de los pueblos fundada en el amor y en el trabajo. La unión de los pueblos que aman y hacen fecunda la tierra.

$* * * *$

Cerramos el libro. Como el Enjolrás de Ariel, sentimos deseo de contemplar el cielo. Es de noche. Las estrellas tiemblan en lo alto como ateridas por el frío de tantos bronces de gloria, y hacia el Sur, la Cruz luminosa de América abre sus brazos en el anhelo de abarcar tanta grandeza presente. Hemos asistido a un "desfile asombroso" de héroes y de cosas. Hombres y mujeres pasaron bajo los arcos triunfales de nuestra admiración y en cada uno de ellos hemos reconocido al glorioso evocado. En esta obra, todo es ajustado y preciso. Todo vive y vibra. El poeta ha sabido evocar, y, lo más importante, sin adulterar la realidad histórica. La lectura de la obra nos ha dejado un gran aliento de optimismo. Tenemos fe en nuestra 
América; tenemos esperanza en nuestros pueblos y mientras el viejo mundo se desangra en una guerra miserable, América entona salmos al trabajo y por todos sus ámbitos se oyen cantar himnos de paz.

Reflexionamos sobre lo leído y es entonces cuando el poeta adquiere jerarquía insospechada. La reflexión nos hace ahondar. El libro está como abierto frente a la memoria que lo recuerda en sus menores detalles. En él encontramos al historiador emotivo, al arqueólogo exhumador de mitos y leyendas fijadas en las piedras descubiertas y por sobre todo eso, al poeta orfebre; al poeta que supo arrancarle el secreto a la roca milenaria, para exaltar la belleza de la línea; al poeta que entre las ruinas y los escombros de civilizaciones muertas, no pierde de vista la estrella y la nube; al poeta, en fin, que ha sabido penetrar el alma autóctona de nuestra América, para consagrar en el verso de serena forma, un panamericanismo espiritual, arrancado al silencio de los siglos muertos, pero renovado con la savia del presente y engrandecido con la esperanza del mañana.

Como dijéramos, América ya tiene su poeta, su auténtico poeta.

Montevideo, Uruguay, 1940.

Prof. Eugento P. Bergara, Montevideo. 
